\title{
A PESQUISA COMO ATIVIDADE DIDÁTICO-PEDAGÓGICA NAS AULAS DE LÍNGUA PORTUGUESA DO ENSINO MÉDIO ${ }^{1}$
}

\author{
Research teaching as educational activity in Portuguese classes of secondary \\ education
}

Edvone SANTOS ${ }^{2}$

Katia Bruginski MULIK,USP ${ }^{3}$

RESUMO: O presente artigo objetiva investigar como a pesquisa é compreendida no âmbito escolar, principalmente na sala de aula de Língua Portuguesa de ensino médio de escolas públicas. Buscamos analisar o discurso da prática pedagógica em relação à pesquisa através de um estudo qualitativo. Como resultado desse estudo, apontamos que a pesquisa científica deve fazer parte do dia a dia dos nossos alunos, em toda e qualquer instituição de ensino básico, como atividade orientada ou sistemática.

PALAVRAS-CHAVES: Pesquisa; Discurso; Ensino Médio; Ensino de Língua Portuguesa.

ABSTRACT: This article investigates how research is understood in the school environment, mainly in the Portuguese Language classroom of public high schools. We analyze the discourse pedagogical practice in relation to research by means of a qualitative study. As a result of this study, we point out that the scientific research should be part of the daily lives of our students in any primary education institution as either an oriented or systematic activity.

KEYWORDS: Research; Discourse; High School; Portuguese Language teaching.

\section{INTRODUÇÃO}

A pesquisa, por ser um instrumento de ensino/aprendizagem que "possibilita aquisição e desenvolvimento de muitas habilidades" (BEZERRA, 2008, p. 3), tais como a argumentação, a reflexão e o senso crítico, seria uma proposta plausível para o

\footnotetext{
${ }^{1}$ Releitura do artigo apresentado como Trabalho de Conclusão de Curso na Graduação em Letras Português-Inglês, 2015, pela Faculdade de Administração, Ciências, Educação e Letras orientado pela professora Msc. Katia Bruginski Mulik. Revisão: Denise Mohr. demohr@yahoo.com.

2 Graduada em Letras Português-Inglês pela Faculdade de Administração, Ciências, Educação e Letras (FACEL). edvone.2010.santos@gmail.com.

3 Doutoranda em Estudos Linguísticos e Literários em Inglês na Universidade de São Paulo (USP); professora de Língua Inglesa na rede pública estadual do Paraná e no curso de Letras e Psicologia na Faculdade de Administração, Ciências, Educação e Letras (FACEL). katiamulik87@ gmail.com.
} 
desenvolvimento das capacidades voltadas para uma formação autônoma, em que os alunos se percebam enquanto produtores do conhecimento e não apenas receptores passivos (MATTOS; CASTANHA, 2009, p. 3, 9-10, grifo nosso).

Partindo desse cenário, o objetivo deste texto consiste em investigar se, nos discursos dos professores (a definição de discurso aqui empregada seria de discurso como fala ou texto que sustenta e ao mesmo tempo é sustentado pela ideologia de um grupo ou instituição social), a pesquisa enquanto atividade didático-pedagógica é desenvolvida ou não em sala de aula de Língua Portuguesa nas escolas públicas de educação básica.

Neste trabalho, entende-se que a pesquisa na escola seria o ato de buscar, de forma sistemática e crítica, percebendo o objeto de estudo como "verdade provisória" (DEL-MASSO et al. 2014, p. 4) e não simplesmente o "querer saber" (SOUZA, 2010, p. 8) ou aquilo que Bagno (1998, p. 18) descreve como rudimento da pesquisa ou "pesquisa do dia a dia".

A metodologia empregada é de natureza qualitativa. A análise, de caráter interpretativista, enfatiza os fatos, significando-os e levando em conta os conflitos, já que tem o homem como sujeito e ator, alguém que tanto individualmente quanto coletivamente interpreta a realidade socialmente construída (SANTOS FILHO, 1997).

Como instrumento para a coleta de dados foi elaborada uma entrevista - que seguiu por e-mail - com questões abertas aplicadas a duas professoras de escolas públicas.

Os resultados deste estudo revelam as práticas das docentes participantes, levando em consideração a autonomia das professoras. Segundo os PCNs $(2008)^{4}$ e as DCNs $(2011)^{5}$, entre outros documentos oficiais, cada professor e instituição de ensino tem autonomia para adaptar as atividades conforme a necessidade e plano de ensino

4 PCNs- Parâmetros Curriculares Nacionais: referências básicas para a elaboração das matrizes de referências na educação brasileira; documento que orienta professores na busca de novas metodologias e abordagens.

5 DCNs - Diretrizes Curriculares Nacionais: documento elaborado para orientar os educadores em relação a alguns aspectos fundamentais de cada disciplina. 
proposto pela própria instituição, cabendo apenas a estes respeitar as "propostas de expectativas de aprendizagem" de cada nível de ensino (CEA, 2012, p. 2 )6.

\section{O USO DA PESQUISA EM SALA DE AULA}

As discussões em torno do que seja pesquisa e o processo valorativo que o sujeito assume frente à construção do conhecimento por meio desse instrumento fazem com que habilidades tais como a argumentação, a reflexão, a criatividade, o posicionamento e o senso crítico, além, é claro, das habilidades organizacionais, comportamentais/sociais e cognitivas sejam potencializadas ou desenvolvidas. (MATTOS; CASTANHA, 2009, p. 9-10).

Considerando os fatores relevantes ressaltados acima, relacionados às contribuições das atividades de pesquisa no ambiente escolar, as perguntas que não poderíamos deixar de fazer são: o que é pesquisa? o que se entende como pesquisa na escola?

No dicionário Aurélio (2002), a palavra "pesquisa" é definida como "ato ou efeito de pesquisar; investigação e estudos, minuciosos e sistemáticos, com o fim de descobrir fatos relativos a um campo do conhecimento".

Tratando da origem desse vocábulo, Bagno (1998, p. 17) afirma que, como todas as línguas modernas derivaram do latim, a palavra pesquisa tem sua origem nessa língua clássica, com a grafia "perquire”. A palavra, com o passar do tempo, se modifica, e "os r passam a serem s". Todavia o significado desse léxico, conforme menciona o autor, permanece o mesmo do latim: "procurar, buscar com cuidado; procurar por toda parte; informar-se; inquirir; perguntar; indagar bem; aprofundar na busca". (BAGNO, 1998, p. 17).

Xavier et al. (2009) colocam que pesquisa é ato fundamental na busca de responder ou explicar determinados assuntos, informações ou indagações, estando a atividade presente em todo momento da vida do ser humano. Essa ação pode ser realizada em grupo ou individualmente, abrangendo sempre aspectos como interesses, critérios, disponibilidade, tempo e senso crítico.

6 CEA - Caderno de Expectativas de Aprendizagem: documento que auxilia no planejamento do professor de escolas estaduais, estabelecendo o que é fundamental ser trabalhado em sala de aula em cada disciplina. 
Em Bagno (1998, p. 18), lemos que pesquisa é "a investigação feita com o objetivo expresso de obter conhecimento específico e estruturado sobre um assunto preciso". Quanto ao papel do pesquisador, Demo (2006) menciona que é ir além da atitude de apenas receber informações, independentemente do nível de ensino, já que é preciso considerar o comprometimento social e político em meio à ação de pesquisar, buscando sempre desenvolver as habilidades mencionadas anteriormente e a união de teoria e prática.

Com relação à atividade de pesquisa dentro da instituição de ensino de educação básica, Demo (2006) explica que a única coisa que diferencia o modo prático ou teórico no ato de pesquisar nesse nível de ensino e no ensino superior é a forma e o processo, pois o que se busca, no decorrer da educação formal, independentemente do nível do aluno, é despertar a competência humana e política desse sujeito.

Santos et al. (2012), por sua vez, ressaltam que a pesquisa em sala de aula possibilita ao aluno expor suas dúvidas, interesses e curiosidades, oportunizando a construção de novos conhecimentos a partir da bagagem de conhecimentos prévios que esse aluno traz.

Já Bochniak (1992, p. 15) e Mattos e Castanha (2009, p. 7) observam que a atividade de pesquisa em sala de aula de educação básica não era muito frequente no final do século XX. O que queremos destacar é que, mesmo estando no século XXI, na era tecnológica, na qual o conhecimento se transforma ininterruptamente, muitos ainda acreditam que o trabalho de pesquisa científica, com sua forma sistemática de investigação minuciosa, que envolve teoria e prática, é para poucos, os que estão inseridos no ensino superior, sendo considerado algo muito difícil para alunos da educação básica. Isso se dá, segundo Mattos e Castanha (2009, p. 7), porque ainda é escassa a "ênfase ou orientações aos educandos, quanto ao encaminhamento dos trabalhos de pesquisa escolar". Além disso, segundo esses autores, "a precariedade na formação continuada dos professores" e o afastamento da temática - pesquisa escolar prejudicam o desenvolvimento de tal atividade em sala de aula de educação básica.

Sousa (2010), no que se refere ao trabalho de pesquisa no Brasil, menciona que esse tipo de atividade tem avançado de forma positiva na esfera da sala de aula, principalmente nas aulas de Língua Portuguesa. Porém nos deparamos com algo negativo, pois, para a autora, "a pesquisa ganhou hoje ares de cotidianidade" e a frase 
"vou pesquisar" tem sido usada para muitas atividades em que se deseja simplesmente saber - por exemplo, "vou saber se amanhã vai chover" é substituída por "vou pesquisar se amanhã vai chover". (SOUSA, 2010, p. 8).

Quando levamos em conta o significado do léxico "saber", que, segundo o dicionário Aurélio (2002), seria “ter conhecimento ou notícia de algo; ser instruído em; reter na memória: saber de cor; indagar, informar-se", compreendemos a diferença entre pesquisar e querer saber. Bagno (1998), a esse respeito, menciona outros exemplos, como consultar jornais para encontrar um emprego, saber astronomia, vender objetos, consultar palavras em dicionário. No sentido de querer saber, são entendidos como sendo rudimento, que é simplesmente o elemento inicial, o começo da pesquisa - ou seja, aquilo que Bagno (1998) chama de pesquisa do cotidiano ou pesquisa do dia a dia e não o ato de pesquisar cientificamente.

A simples consulta ao relógio para ver que horas são, ou a espiada para fora da janela para observar o tempo que está fazendo, ou a batidinha na porta do banheiro para saber se tem gente dentro... Todos estes são rudimentos de pesquisa. (BAGNO, 1998, p. 18)

Voltando ao assunto pesquisa, no final do século XX Bagno chama a atenção dos professores que requisitam o trabalho de pesquisa, levantando de forma crítica questões que nos possibilitam refletir sobre a forma como muitos professores encaram o trabalho de pesquisa em sala de aula: "pesquisar só por pesquisar? Só porque a secretaria de ensino pede? Só porque virou modismo pedagógico?”. (BAGNO, 1998, p. 22).

Infelizmente essas perguntas parecem ainda ecoar no século XXI, quando nos vemos frente ao desafio da atividade de pesquisar ou aplicar a atividade de pesquisa em sala de aula de educação básica. Em muitas situações, nos deparamos com uma prática pedagógica aplicada de modo disfuncional, pois não visa o lado crítico-reflexivo, a compreensão ou a tomada de decisões em situações múltiplas, ou seja, em muitos momentos, o trabalho de pesquisa é apenas para saber o que o aluno sabe. Dessa forma, os professores acabam propondo, como afirma Bagno (1998, p. 15), atividades que servem apenas para "garantir notas e passar de ano", ou seja, recomendam atividades puramente para saber o que se sabe e não para complementar, com auxílio e orientação, indicando aos alunos como irão realizar a pesquisa, quantos autores diferentes devem consultar, como irão disponibilizar no papel tudo isso. 
O foco nas atividades de pesquisa, principalmente nas aulas de Língua Portuguesa, parece pontuar, primordialmente, que os alunos não fujam do assunto, mantenham a concordância verbal e nominal, usem a acentuação correta e tantas outras regras normativas. Os professores esquecem de assuntos relevantes, que poderiam gerar facilidade no desenvolvimento do trabalho de pesquisa e na vida futura dos alunos, ponto que, segundo Del-Masso et al. (2014), envolve o grau de consciência do que investigar, escolher, definir, recortar, em relação a uma dada realidade, além, é claro, da sistematização, exposição, fichamento, referencial do material utilizado, etc. Cabe lembrar que tudo isso deve estar dentro de um modelo, que segue o método necessário para compor o trabalho de pesquisa científica, uma atividade em que a argumentação e a criticidade são fatores relevantes.

\section{TIPOS DE PESQUISA}

Em relação aos tipos de pesquisa escolar que abrangem não somente a disciplina de Língua Portuguesa, temos os seguintes quadros, elaborados a partir das propostas de Bezerra (2008, p. 1-2) e Mattos e Castanha (2009, p. 4-5):

\section{Quadro 1 - Tipos de pesquisa escolar}

\begin{tabular}{|l|l|}
\hline \multicolumn{1}{|c|}{ TIPOS DE PESQUISA } & \multicolumn{1}{|c|}{ CARACTERIZAÇÃO } \\
\hline Bibliográfica & $\begin{array}{l}\text { Realizada por meio de análise, descrição e } \\
\text { comparação de textos. }\end{array}$ \\
\hline De campo ou estudo do meio & $\begin{array}{l}\text { Feita por observação e comparação no próprio } \\
\text { local. }\end{array}$ \\
\hline De mercado & $\begin{array}{l}\text { Investigação dos hábitos dos consumidores, } \\
\text { aceitação e venda de um produto. }\end{array}$ \\
\hline De opinião & Investigação do gosto e preferência das pessoas. \\
\hline Descritiva & $\begin{array}{l}\text { Descrição passo a passo da transformação } \\
\text { periódica. }\end{array}$ \\
\hline Histórica & \begin{tabular}{l} 
Busca de informações sobre o passado. \\
\hline Experimental
\end{tabular} \\
\hline
\end{tabular}

Fonte: Bezerra (2008)

Em Mattos e Castanha (2009), as pesquisas de mercado, de opinião, descritiva, histórica não são mencionadas ou não são nomeadas da mesma forma. As autoras, todavia, mencionam as demais e subdividem a pesquisa de campo em: 
Quadro 2 - Tipos de pesquisa de campo

\begin{tabular}{|l|l|}
\hline Pesquisa-ação & $\begin{array}{l}\text { Discussão, exame, que tem como objetivo uma } \\
\text { intervenção no mundo real. }\end{array}$ \\
\hline Pesquisa participante & $\begin{array}{l}\text { Propõe um intenso envolvimento do } \\
\text { pesquisador nas diversas fases da pesquisa. } \\
\text { Objetivo: avaliar os resultados, visando } \\
\text { transformá-los em ações concretas. }\end{array}$ \\
\hline Pesquisa etnográfica & $\begin{array}{l}\text { Seria a obtenção de grande quantidade de } \\
\text { dados descritivos, utilizando principalmente a } \\
\text { observação da situação e das pessoas ou grupo } \\
\text { selecionado. }\end{array}$ \\
\hline
\end{tabular}

Fonte: Mattos e Castanha (2009)

Ao refletir sobre essas duas propostas, acreditamos que não sejam conflitantes, e sim elementos ou definições que se completam quando se pensa nos tipos de pesquisa em sala de aula de educação básica. Apesar disso, observamos em inúmeros discursos que os três últimos tipos de pesquisa são mais recorrentes no ensino superior, algo que acreditamos ser preconceito, por conta da história da pesquisa e do porquê se realiza pesquisa nas universidades.

\section{METODOLOGIA}

A metodologia empregada para realizar este estudo é de natureza qualitativa. A análise, de caráter interpretativista, visa enriquecer as discussões referentes ao modo como vem sendo trabalhada a pesquisa em sala de aula. Ao analisar os dados coletados, fizemos recortes dos textos de Bezerra (2008), Mattos e Castanha (2009), Portilho e Almeida (2008), Santos et al. (2012) e Bagno (1998).

E qual seria a justificativa para esses textos? Podemos afirmar que o uso desses quatro textos justifica-se por dialogarem entre si ao trazerem luz às discussões existentes e experiências vividas no que se refere à prática pedagógica da pesquisa em sala de aula de educação básica. Além disso, em cada voz de autoridade aqui mencionada - que debate o assunto pesquisa em sala de aula -, percebemos a relevância do papel da pesquisa na sociedade: em Bagno (1998), tem-se o relato de pai, que seria o próprio Bagno, frente ao desafio de auxiliar o filho na atividade de pesquisa escolar, algo que o leva a realizar severas críticas ao sistema de ensino, independentemente de 
ele ser público ou privado; em Mattos e Castanha (2009), Portilho e Almeida (2008), Santos et al. ( 2012), a perspectiva de discutir a prática da pesquisa transcende a barreira do lar, indo ao encontro de outro ambiente, a sala de aula de educação básica, analisada pelo ângulo do próprio professor, que se vê envolvido no grande desafio de pensar e repensar a prática da pesquisa em sala de aula. Já em Bezerra (2008), a posição encontrada é a de um mestre em Educação que volta o seu olhar para as $\operatorname{LDBs}^{7}$ e os PCNs para examinar como esses documentos mencionam a atividade de pesquisa.

Quanto à escolha dos sujeitos participantes, a princípio tentamos marcar horário e local para entrevistar cinco professores de Língua Portuguesa do ensino médio de diferentes escolas estaduais - pessoas conhecidas e outras indicadas por amigos -, o que se deu por e-mail e telefone. No entanto, encontramos grandes dificuldades para marcar horários com esses professores para entrevistá-los, tendo como desafio conciliar o prazo curto para a realização deste estudo e o entrave da segunda paralisação das escolas estaduais, que teve início exatamente no mês de maio de 2015. Por esse motivo, optamos pelo procedimento da coleta de dados virtual, ou seja, mandamos por e-mail as questões, porém acrescentamos outros três professores. Foram nove formulários repassados por e-mail, mas apenas dois sujeitos reenviaram os e-mails com as respostas. Os demais professores, mesmo tendo sido relembrados por telefone ou e-mail acerca do questionário, não puderam, ou não quiseram, responder. Dessa forma, considera-se bem limitada a amostra aqui estudada.

Ainda em se tratando dos participantes, ambos os professores respondentes são do sexo feminino. O tempo de atuação na educação básica da professora 1, que trabalha 40 horas semanais, é de onze anos; já a professora 2 leciona há quatro anos e sua carga horária é de 25 horas semanais. Ambas têm investido em formação continuada, cursando ou tendo cursado pós-graduação na área educacional.

$\mathrm{O}$ instrumento utilizado para a coleta de dados foi composto por cinco questões abertas. Um dos sujeitos participantes respondeu a todas e o outro deixou apenas uma sem resposta. As perguntas foram as que seguem:

7 LDBs - Lei de Diretrizes e Bases da Educação Nacional. Regulariza e define a educação brasileira com base na constituição deste país, Brasil. 
1. Você costuma solicitar ou trabalhar com pesquisa nas aulas de Língua Portuguesa no ensino médio?

2. Explique sobre os tipos de pesquisa e de que forma ela costuma ser desenvolvida: com que frequência, se em grupos ou individual, se é feita na escola, em casa/ biblioteca, quais conteúdos costuma envolver, quais são os objetivos (fichamento de livros, apresentações de determinado conteúdo).

3. Como você costuma a orientar os alunos para a atividade de pesquisa? Você indica referência/ livros/ links para a leitura? Informa os passos ou fornece um roteiro para elaboração dos trabalhos?

4. Existe alguma dificuldade em se trabalhar com pesquisa? (ex.: número de alunos por turma, falta de material, laboratório de informática, etc.)

5. Em sua opinião, qual a importância do trabalho com pesquisa na escola?

\section{APRESENTAÇÃO E DISCUSSÃO DOS DADOS}

Ambas as participantes afirmam trabalhar com pesquisa em sala de aula. Com relação aos tipos de pesquisa que as entrevistadas utilizam, nos deparamos com um discurso vago. Possivelmente com maior contato e discussões seria possível obter uma resposta ou a reformulação do discurso, porém aqui as respostas não nos possibilitaram conhecer qual seria o tipo de pesquisa efetivamente realizada em sala de aula de Língua Portuguesa em que elas atuam, ficando apenas subtendido que seria a pesquisa bibliográfica. Em lugar de clareza sobre o tipo de pesquisa, o que percebemos são justificativas sobre a forma, o aspecto e o objetivo do trabalho de pesquisa.

Professora 1 - [...] o conteúdo de literatura é bastante extenso, por isso em alguns momentos peço que façam uma prévia do conteúdo que irei trabalhar [...]. Geralmente peço que a pesquisa seja feita individualmente e em seguida, na sala de aula, é que desenvolvemos o trabalho, que pode ser tanto individual como em equipes ou duplas. Normalmente o objetivo deste tipo de pesquisa é adiantar o conteúdo: assim já ficam por dentro do que vai ser abordado.

Professora 2 - Quando realizo trabalhos de pesquisa, tento envolver vários aspectos $e$ de diferentes formas, para que os alunos tenham possibilidades distintas de ensino [...]. Às vezes solicito trabalhos de pesquisa de autores relacionados aos gêneros textuais trabalhados em sala.

Percebemos, ao analisar as respostas ou discurso das professoras participantes, que, apesar de ambas concordarem que a pesquisa é uma atividade relevante para o ensino/aprendizagem, a definição do tipo de pesquisa não parece ser importante quando se trata de pesquisa escolar, pois fica apenas subentendido ou implícito que a pesquisa bibliográfica é a pesquisa recomendada por elas em sala de aula. Em relação ao tipo de pesquisa, isso não vai ao encontro do que afirma Bagno (1998): mesmo na atividade de 
pesquisa escolar, é indispensável pensar e repensar a metodologia e o tipo de pesquisa, pois para cada objetivo ou proposta existem diferentes modos de coletar os dados.

Voltemos um instante aos discursos das professoras para refletir sobre a maneira ou em quais conteúdos os alunos são convidados a participar do trabalho de pesquisa em sala de aula. Pelo discurso da professora 1 percebemos que um dos temas para o qual a pesquisa é requisitada é o "conteúdo de literatura", enquanto no discurso da professora 2 o conteúdo são os "gêneros textuais".

Quando consideramos os conteúdos a serem trabalhados em sala de aula de Língua Portuguesa propostos nos documentos oficiais, percebemos que vão além dos mencionados por nossos sujeitos participantes. Bezerra (2008, p. 11) enfatiza que nos PCNs os conteúdos para os quais podem ser sugeridas atividades de pesquisas seriam "Valores, normas e atitudes; gêneros discursivos; práticas de leitura; prática de produção de texto; análise e reflexão sobre a língua", trabalhados em cada ciclo do ensino de Língua Portuguesa, de forma a aumentar o grau de dificuldade gradativamente para cada fase do ensino/aprendizagem, já que o aluno precisa acostumar-se com certas habilidades e ações que o beneficiem em seu futuro acadêmico.

Em relação ao objetivo de solicitar o trabalho de pesquisa, nos discursos de ambas as professoras verificamos que a tarefa teria como objetivo adiantar ou aprofundar o conteúdo, de forma que os alunos tivessem contato com o tema a ser explorado em aulas posteriores.

A respeito de por que sugerir trabalho com pesquisa em sala de aula, Bezerra (2008, p. 3) vai dizer que entre os propósitos estão o de proporcionar intervenção no trabalho escolar e fazer uso de uma série de itens que ultrapassam o trabalho em sala de aula. Além disso, a autora acrescenta que o professor, ao propor que o aluno pesquise sobre o tema estudado, afasta-se do tão criticado método de repetição e transmissão de conteúdos, criando possibilidades para que seus alunos apresentem o conteúdo com o seu próprio discurso.

Outro ponto colocado pelas professoras participantes diz respeito à sugestão ou pedido de atividade de pesquisa aos alunos. No discurso de uma delas, podemos constatar a prática de questionar, para, a partir disso, inserir os alunos na atividade de pesquisa, porém de modo bem direcionado, enquanto que, no outro discurso, a atitude de indagar não é mencionada. 
Professora 1- peço que façam uma prévia do conteúdo que irei trabalhar[...] indico obras e direciono bem o que quero contemplar naquele momento, assim o aluno já vem preparado para a aula em que farei minha exposição.

Professora 2 - Às vezes lanço algumas perguntas sobre o tema que estamos estudando e peço que pesquisem em casa e tragam a resposta na aula seguinte.

A respeito disso, Portilho e Almeida (2008, p. 481) afirmam que é relevante e recomendável que a atividade de pesquisa se dê a partir de questionamentos e não a partir de um tema, pois, segundo as autoras, a proposta de partir de um tema "serve apenas para prestigiar o tão temido copie e cole" nas atividades de pesquisa dos estudantes.

Outra questão colocada para as professoras diz respeito à orientação dos alunos e à indicação de referências e roteiro para elaboração da atividade de pesquisa. Ambas relatam que são indicadas fontes confiáveis para que os alunos consultem e conheçam mais sobre o tema proposto em sala de aula, seguindo um roteiro apresentado pelas docentes.

Professora 1 - Geralmente sim. Começamos pelo livro didático, que mostra links, vídeos e até mesmo referências bibliográficas. Elaboro um roteiro a fim de que o aluno se direcione exatamente para o que preciso.

Professora 2 - Depois de trabalhar o conteúdo, mostrar exemplos e fontes confiáveis sobre o tema [...], forneço um roteiro e, na medida do possível, vou tirando as principais dúvidas dos alunos.

Em relação às dificuldades encontradas para trabalhar com pesquisa, foram mencionadas: a falta de dedicação dos alunos, o número elevado de alunos em sala de aula, a falta de hábitos de leitura e de estudar em casa, a falta de material, o pouco espaço e material nos laboratórios de informática.

Professora 1 - [...] os alunos não têm dedicação suficiente para que o trabalho se concretize efetivamente. Muitos [...] copiam dos colegas $e$ isso não é produtivo.

Professora 2 - [...] são vários os motivos [...] Um dos principais é o número elevado de alunos em sala de aula [...] Infelizmente, a maioria dos nossos alunos não têm o hábito de estudar em casa, de ler diferentes materiais [...] se a turma é muito grande [...] falta material, a sala de informática torna-se pequena.

Encontramos no discurso de Mattos e Castanha (2009, p. 7) exatamente os itens problemáticos que aparecem no discurso das professoras participantes: atividades de 
pesquisa como cópia de outros materiais já existentes, nas quais não são mencionadas as fontes de pesquisas e o autor, nem se empregarm aspas; a precariedade de materiais nas bibliotecas escolares; a inexistência de computadores para o número de alunos de cada turma. Todavia, como descrevem Mattos e Castanha (2009), não são apenas esses os problemas enfrentados por professores de escolas públicas e até mesmo particulares, já que em muitos momentos o professor depara-se com comunidades em que "a carência dos alunos quanto à aquisição de livros, o acesso à internet, a falta de orientação nas atividades de pesquisa por parte dos auxiliares de biblioteca" e, é claro, o despreparo do professor para auxiliar o aluno acentuam a problemática do desenvolvimento, desempenho ou até mesmo da prática de pesquisa em sala de aula de Língua Portuguesa. (MATTOS; CASTANHA, 2009, p. 13).

Em se tratando do despreparo do professor, segundo as autoras esse profissional muitas vezes tem dificuldade não somente em orientar os alunos, mas também em realizar suas próprias pesquisas, por causa da precariedade em suas orientações na graduação ou nos estudos subsequentes, algo que dificulta o desenvolvimento da atividade de pesquisa sistemática em sala de aula.

A última pergunta que compôs o questionário refere-se à importância do trabalho com pesquisa. Como a professora 1 não respondeu, temos apenas a resposta da professora 2, para quem o trabalho de pesquisa deve ter início ainda nos primeiros anos do ensino infantil. Sua relevância se dá primordialmente por possibilitar a vivência das habilidades de questionar, buscar respostas e ser mais precisos ao serem abordados ou estimulados a fazer alguma atividade.

\section{Professora 1 - NÃO RESPONDEU}

Professora 2 - É muito importante, mas deve ser feito desde que o aluno inicia a sua vida escolar. Através da pesquisa os alunos aprendem a questionar os fatos, buscar outras respostas e, também, a ser mais objetivos e concisos, pois, quando solicitamos trabalho de pesquisa, muitas vezes, eles não sabem quais são as informações importantes e quais são relevantes $e$ assim abordam aspectos desnecessários, por falta do hábito de pesquisar.

Para finalizarmos esta etapa, queremos destacar que na análise aqui realizada pudemos perceber que nós, como professores, em muitos momentos tentamos demonstrar em nosso discurso quanto atividades relevantes fazem parte do nosso cotidiano profissional, porém continuamos atrelados a um discurso vago, em que as nossas próprias ações e palavras não condizem com os valores que defendemos ou 
idealizamos. Um outro ponto observado é que, segundo os discursos dessas professoras, não há um trabalho de pesquisa condizente com o que defendemos aqui neste texto: o que compreendemos existir nas salas de aulas dessas participantes é o que Bagno (1998) chama de rudimento da pesquisa.

\section{CONSIDERAÇÕES FINAIS}

O presente artigo buscou analisar, ainda que superficialmente, o discurso de professores de Língua Portuguesa de escolas públicas acerca da prática pedagógica referente ao trabalho com pesquisa para a referida disciplina. Para tanto, realizou-se a leitura das respostas das questões propostas por e-mail para essas duas professoras, atuantes no ensino médio.

Os resultados do estudo revelam que a pesquisa faz parte, sim, das práticas das participantes, porém de forma rudimentar. O que percebemos ainda é que existem muitas dificuldades para que o trabalho com pesquisa alcance maior rendimento, aplicabilidade e qualidade na vida dos alunos e até mesmo dos professores de educação básica, de forma a fornecer subsídios para que as habilidades sejam desenvolvidas, assim como a própria autonomia do aluno na construção do conhecimento.

A contribuição deste artigo se dá em função das discussões teóricas e analíticas relacionadas a alguns discursos existentes sobre o que seja pesquisa e os tipos de pesquisa, principalmente no contexto escolar, e dos seus desdobramentos para novos trabalhos no campo educacional. Apesar de não termos conseguido efetivamente responder à pergunta sobre os tipos de pesquisa encontrados em sala de aula de Língua Portuguesa da educação básica de forma mais esclarecedora e específica, pudemos demonstrar que a pesquisa bibliográfica, supostamente, tem um lugar de destaque nessa disciplina.

Outro fator relevante que encontramos em nosso estudo é o discurso de quanto seria produtivo para os alunos discutirem em sala de aula o que é pesquisa e o que caracteriza essa atividade, de forma que esses indivíduos compreendam que não é um trabalho, simplesmente, de querer saber ou algo rudimentar, e sim uma atividade sistemática, que requer engajamento, disponibilidade e interesse de percorrer diferentes 
etapas na busca de responder aos questionamentos e construir o conhecimento que levará os alunos para as etapas futuras de sua vida educacional e profissional.

Por fim, acreditamos que a atividade de pesquisa tem papel essencial na construção do sujeito, possibilitando o desenvolvimento de habilidades construtivas, a formação autônoma, o compromisso social e político no processo emancipatório de todo indivíduo. Ela pode e deve ser realizada de forma produtiva na escola, já que o processo, a trajetória rumo ao elemento final é tão relevante quanto a composição final. Trabalhar as etapas da construção de um projeto de pesquisa, a organização, o cronograma, o fichamento, a orientação, o mapeamento do material que servirá de referencial teórico, entre tantos outros elementos, fará com que esse processo - que não é um único ato, e sim algo contínuo - seja ponte para o conhecimento autônomo e provisório e também para o desenvolvimento das habilidades objetivadas, efetivamente.

\section{REFERÊNCIAS BIBLIOGRÁFICAS}

BAGNO, M. Pesquisa na escola: o que é e como se faz. São Paulo: Loyola, 1998.

BEZERRA, M. A.C. A pesquisa escolar nas LDBs e nos PCNs. 2008. Encontrado em: $\langle$ http://revista.crb8.org.br/index.php/crb8digital/article/viewFile/15/15 > . Acesso em: 15 maio 2015.

BOCHNIAK, R. Conversando com Ivani Fazenda sobre a organização desta coletânea. In: FAZENDA, Ivani (Org.). Novos enfoques da pesquisa educacional. São Paulo: Cortez, 1992.

BRASIL. Ministério da Educação. Secretaria de Educação Básica. Diretrizes Curriculares Nacionais Gerais da Educação Básica. 2011. Encontrado em: $\langle$ http://portal.mec.gov.br/index.php?option=com_docman\&task=doc $>$. Acesso em: 10 abr. 2015.

Parâmetros curriculares nacionais: ensino médio (Parte I) 2000. Encontrado em: <http://portal.mec.gov.br/seb/arquivos/pdf/blegais.pdf > Acesso em: 10 abr. 2015.

DEL-MASSO, M. C. S.; COTTA, M. A. C.; SANTOS, M. A. P. Pesquisa científica e o senso comum. 2014. Encontrado em <http://www.acervodigital.unesp.br/bitstream/ unesp/155305/1/unesp-nead_reei1_ei_d04_texto1.pdf>. Acesso em: 30 maio 2015.

DEMO, P. Pesquisa: princípio cientifico e educativo. Biblioteca da Educação. Série 1. Escola; v. 14. 12. ed. São Paulo: Cortez, 2006.

FERREIRA, A.B.H. Minidicionário da língua portuguesa. Rio de Janeiro: Nova Fronteira, 2002.

MATTOS, E. M. A.; CASTANHA, A. P. A importância da pesquisa escolar para a construção do conhecimento do aluno no ensino fundamental. 2009. Encontrado em: $\langle$ http://www.diaadiaeducacao.pr.gov.br/portals/pde/arquivos/2525-6.pdf $>$. Acesso em: 15 maio 2015. 
PARANÁ. Secretaria de Estado da Educação. Caderno de expectativas de aprendizagem (Departamento de Educação Básica). 2012. Encontrado em: <http://www.educadores.diaadia.pr.gov.br/arquivos/File/diretrizes/caderno_expectativas. pdf>. Acesso em: 16 mar. 2015.

PORTILHO, E. M. L.; ALMEIDA, S. C.D. Avaliando a aprendizagem e o ensino com pesquisa no Ensino Médio. Ensaio: aval.pol. públ. Educ. [online]. 2008, vol. 16, n. 60, p. 469-488. ISSN 0104-4036. http://dx.doi.org/10.1590/S0104 - 40362008000300009. Encontrado $\quad \mathrm{em}:<$ http://www.scielo.br/scielo.php?script=sci_arttext\&pid=S010440362008000300009> ou <http://www.scielo.br/pdf/ensaio/v16n60/v16n60a09.pdf>. Acesso em: 05 jan. 2015.

SANTOS, A.C.T.; ZACCA, A.; GOULART, L. B. Trabalhando com pesquisa em sala de aula. Revista e - Ped - Facos/ CNEC Osório vol. 2 - n 1 - ago. 2012 - ISSN22377077.Encontrado em: <http://facos.edu.br/publicacoes/revistas/ eped/agosto_2012/ pdf/trabalhando_com_pesquisa_em_sala_de_aula.pdf>. Acesso em: 30 abr. 2015.

SANTOS FILHO, J.C. Pesquisa educacional: qualitativa-quantitativa. Coleção: Questões da Nossa Época. 2. ed. São Paulo: Cortez, 1997.

SOUSA, M.E.V. Pesquisa aplicada ao ensino de língua portuguesa. 2010. Encontrado em:

<http://portal.virtual.ufpb.br/bibliotecavirtual/files/pesquisa_aplicada_ao_ensino_de_lp _1360183055.pdf>. Acesso em: 28 mar. 2015.

XAVIER,G.K.R.S; BRITO,A.P; CASIMIRO, K.F. A pesquisa no ensino fundamental: fonte para construção de conhecimento. 2009. Encontrado em: 〈http://www.educacaopublica.ri.gov.br/biblioteca/educacao/0225.html >. Acesso em: 02 jan. 2015. 